\title{
SOSIALISASI DAN PELATIHAN RAINWATER HARVESTING (RWH) DI SDN MERUYA UTARA 12, 13 PAGI DAN 15 PETANG
}

\author{
Sirin Fairus ${ }^{1 *}$, Diki Surya Irawan ${ }^{2}$, Prismita Nursetyowati ${ }^{3}$ \\ 123 Program Studi Teknik Lingkungan, Fakultas Teknik dan IImu Komputer \\ Universitas Bakrie, Jakarta, Indonesia \\ E-mail: 1sirin.fairus@bakrie.ac.id *,2diki.surya@bakrie.ac.id, 3prismita.nursetyowati@bakrie.ac.id \\ Received: February 17, 2020 / Revised: June 29, 2020 / Accepted: June 30, 2020 \\ DOI: https://doi.org/10.36782/ijsr.v2i1.18
}

\begin{abstract}
ABSTRAK
Air hujan merupakan salah satu sumber daya air bersih potensial di perkotaan, seperti DKI Jakarta, yang belum dimanfaatkan secara optimal. Terkait hal tersebut, telah dilakukan kegiatan pengabdian kepada masyarakat dengan tema Rainwater Harvesting (RWH). Agenda ini ditujukan untuk memberi edukasi dan pemahaman tentang RWH kepada para guru dan murid SDN Meruya Utara 12, 13 Pagi dan 15 Petang agar dapat melakukan konservasi air hujan dalam rangka penyediaan air bersih. Rangkaian kegiatan terdiri dari sosialisasi dan pemasangan instalasi RWH di sekolah dengan kapasitas total 2000 L, dilanjutkan dengan pelatihan kepada warga sekolah terkait bagaimana prinsip kerja, bagaimana mengoperasikan dan memelihara alat RWH tersebut. Instalasi RWH tersebut terdiri dari 2 buah tangki air bersih dengan masingmasing kapasitas tampung $1000 \mathrm{~L}$ yang diletakan di bagian depan sekolah untuk keperluan cuci tangan dan di mushola untuk keperluan berwudhu. Massa air hujan yang tertampung kemudian didistribusikan ke 2 buah tangki filter untuk dilanjutkan masuk ke dalam tangki penyedia air bersih agar siap digunakan pada waktu pada musim kemarau. Setelah alat RWH sudah diuji coba, warga sekolah dapat merasakan manfaat alat pemanen air hujan ini, karena dapat mengurangi volume jatuhnya air hujan yang cukup besar dari atap gedung sekolah dan limpasan air (run off) yang terjadi di area sekolah sehingga menghindari terjadinya banjir. Alat ini ternyata mampu menyediakan air bersih yang relatif lebih jernih dan mencukupi sehingga bisa mengurangi kebutuhan penggunaan air tanah untuk keperluan sehari-hari. Melalui program ini, warga sekolah telah memahami prinsip kerja, cara pengoperasian, pemeliharaan serta dapat merasakan manfaat dari RWH ini.
\end{abstract}

Kata kunci: pemanenan air hujan, penyediaan air bersih, RWH, run off

\begin{abstract}
Rainwater is one of the potential clean water resources in urban areas, such as DKI Jakarta, which has not been used optimally. Related to this, community service activities had been carried out raising theme Rainwater Harvesting (RWH). This agenda was aimed to give education and understanding of RWH to teachers and students of SDN Meruya Utara 12, 13 Pagi and 15 Petang as one way how to conserve rainwater to provide clean water. These activities consisted of the socialization and installation of RWH in schools with a total capacity of $2000 \mathrm{~L}$, where each $1000 \mathrm{~L}$ placed at the front of the school for hand washing and in the mosque for ablution purposes. Then agenda was continued with training how to work, to
\end{abstract}


operate and to maintain the RWH equipment. The mass of collected rainwater was distributed into 2 filter tanks before entering the clean water supply tank and ready for use during the dry season. After the RWH had been tested, school residents could feel the benefits. It could reduce the volume of rainwater falling down from the roof of the school building and run-off that occured in the school area so as to avoid flooding. This instalation was able to provide sufficient clean water so that it could reduce the need for using groundwater for daily use. Through this program, school residents have understood the principles of work, how to operate, maintain and can benefit from this RWH.

Keywords: clean water supply, rainwater harvesting, run off, RWH

\section{PENDAHULUAN}

Pada umumnya jumlah air di bumi sangat banyak, namun jumlah air bersih yang tersedia belum dapat memenuhi permintaan sehingga banyak orang menderita kekurangan air.

Chiras (2009) menyebutkan bahwa kekurangan air dipicu naiknya permintaan seiring peningkatan populasi, tidak meratanya distribusi air, meningkatnya polusi air dan pemakaian air yang tidak efisien. Beberapa penelitian mengindetifikasi bahwa pada atas rumah tangga kekurangan air diperburuk kebocoran air akibat kerusakan home appliances yang tidak segera diperbaiki, pemakaian home appliances yang boros air, perilaku buruk dalam pemakaian air, dan minimnya pemanfaatan air hujan sebagai sumber air alternatif. Pemakaian air yang tidak terkontrol akan mengancam keberlanjutan air, sehingga perlu dilakukan konservasi air. Salah satu metode konservasi air dalam rumah tangga adalah memanen air hujan, yaitu mengumpulkan, menampung dan menyimpan air hujan.
Hujan merupakan uap air yang terkondensasi dan jatuh dari atmosfer ke bumi dengan segala bentuknya dalam rangkaian siklus hidrologi. Jika air yang jatuh berbentuk cair disebut hujan dan jika berupa padat disebut salju. Syarat terjadinya hujan yaitu tersedia udara lembab dan sarana sehingga terjadi kondensasi (Achmad, 2011).

Air hujan merupakan salah satu sumber daya alam yang selama ini belum termanfaatkan secara optimal dan hanya dibiarkan mengalir ke saluran-saluran drainase menuju ke sungaisungai yang akhirnya mengalir ke laut. Jika mampu diolah dan dikelola dengan baik, air hujan tersebut akan memiliki banyak manfaat bagi keberlangsungan hidup manusia, terutama untuk keberlangsungan penyediaan air bersih di masyarakat, Air hujan sendiri dapat digunakan untuk memenuhi berbagai keperluan manusia antara lain untuk mandi, mencuci bahkan untuk air minum (Latif, 2012; Sharpe \& Swistock, 2008). Pemanenan air hujan (Rainwater Harvesting) merupakan metode atau teknologi yang digunakan untuk mengumpulkan air hujan 
yang berasal dari atap bangunan, permukaan tanah, jalan atau perbukitan batu dan dimanfaatkan sebagai salah satu sumber suplai air bersih (UNEP, 2001; Abdulla \& Al-Shareef, 2009). Air hujan merupakan sumber air yang sangat penting terutama di daerah yang tidak terdapat sistem penyediaan air bersih, kualitas air permukaan yang rendah serta tidak tersedia air tanah (Abdulla \& Al-Shareef, 2009).

Memanen air hujan merupakan alternatif sumber air yang sudah dipraktekkan selama berabad-abad di berbagai negara yang sering mengalami kekurangan air (Liaw \& Tsai, 2004). Kualitas air hujan umumnya sangat tinggi (UNEP, 2001). Air hujan hampir tidak mengandung kontaminan, oleh karena itu air tersebut sangat bersih dan bebas kandungan mikroorganisme. Namun, ketika air hujan tersebut kontak dengan permukaan tangkapan air hujan (catchment), tempat pengaliran air hujan (conveyance) dan tangki penampung air hujan, maka air tersebut akan membawa kontaminan baik fisik, kimia maupun mikrobiologi.

Beberapa literatur menunjukkan simpulan yang berbeda mengenai kualitas Penampungan Air Hujan (PAH) dari atap rumah. Kualitas PAH sangat bergantung pada karakteristik wilayah PAH seperti topografi, kondisi cuaca, tipe wilayah tangkapan air hujan, tingkat pencemaran udara, tipe tangki penampungan dan pengelolaan air hujan (Kahinda, Taigbenu, \& Boroto, 2007).
Menurut Horn \& Helmreich (2009), di daerah pinggiran kota atau di pedesaan, umumnya air hujan yang ditampung sangat bersih, tetapi di daerah perkotaan dimana banyak terdapat area industri dan padatnya arus transportasi, kualitas air hujan sangat terpengaruh sehingga mengandung logam berat dan bahan organik dari emisi gas buang. Selain industri dan transportasi, permukaan bahan penangkap air hujan juga mempengaruhi kualitas airnya.

Sazaki, Alexopoulos dan Leotsinidis (2007) menuliskan bahwa parameter kimia dan mikrobiologis menunjukkan fluktuasi musiman. Analisis komponen utama mengungkapkan bahwa parameter mikrobiologis dipengaruhi terutama oleh tingkat kebersihan daerah tangkapan air, sedangkan parameter kimia dipengaruhi oleh kedekatan laut dan aktivitas manusia.

SDN Meruya Utara 12, 13 Pagi dan 15 Petang merupakan SD Negeri di Meruya, Jakarta Barat yang berada di dalam satu kompleks bersama. Sumber air SDN Meruya Utara 12, 13 Pagi dan 15 Petang juga berasal dari sumur bor air tanah, karena pasokan air bersih dari penyedia air (PDAM) setempat kurang mencukupi. SDN Meruya Utara 12, 13 Pagi dan 15 Petang juga memiliki Instalasi Rainwater Harvesting (RWH) untuk membantu penyediaan air di sekolah, namun saat ini sedang tidak aktif karena ada beberapa bagian yang perlu direvitalisasi. 
Untuk itu, dilakukan kegiatan pengabdian kepada masyarakat yang bertujuan untuk meningkatkan kuantitas dan kualitas pasokan air bersih melalui revitalisasi Instalasi RWH yang telah ada. Selain itu, pengabdian masyarakat ini juga bertujuan memberi edukasi dan pemahaman kepada warga SDN Meruya Utara 12, 13 Pagi dan 15 Petang terkait pentingnya air bersih dan pemanenan air hujan untuk penyediaan air bersih dan memberikan pelatihan pembuatan, prinsip kerja, cara operasi dan pemeliharaan Instalasi RWH.

\section{METODOLOGI}

Program ini merupakan salah satu wujud pengabdian terhadap masyarakat dalam penyediaan air bersih melalui pemanenan air hujan yang dilaksanakan di Sekolah SDN Meruya Utara 12 Pagi, SDN Meruya Utara 13 Pagi dari Juli 2018 sampai Januari 2019. Program ini dilaksanakan dalam tiga bagian utama.

Tahap pertama adalah proses pra desain. Tahap pra desain meliputi observasi lapangan dan pembuatan desain RWH serta Rancangan Anggaran Biaya (RAB), yang dilaksanakan dari Juli sampai September 2018. Pada tahap pra desain, langkah awal yang dilakukan adalah observasi lapangan dan penetapan daerah berdasarkan pengamatan awal. Tim Dosen dan Mahasiswa Teknik Lingkungan Universitas Bakrie beserta perwakilan dari PT. Palyja melakukan pengamatan awal pada hari Kamis, 19 Juli 2018 di SDN Meruya Utara 12 Pagi, SDN Meruya Utara 13 Pagi, dan SDN Meruya Utara 15 Petang.

Tahap kedua adalah revitalisasi Instalasi RWH dengan pembuatan alat filtrasi sederhana sebagai bagian dari RWH. Tahap ini dilakukan pada Oktober sampai Desember 2018.

Tahap ketiga dilakukan berbarengan dengan proses revitalisasi, yaitu tahap sosialisasi dan pengontrolan. Sosialisasi pertama kepada warga sekolah dilakukan pada Oktober 2018 mengenai pentingnya air bersih dan pengenalan konsep RWH sebagai alternatif penyediaan air bersih. Pada November 2018, dilakukan sosialisasi kedua yang merupakan edukasi teknis melalui pelatihan pembuatan, prinsip kerja, cara operasi dan pemeliharaan Instalasi RWH. Pengontrolan dilakukan setelah Instalasi RWH selesai direvitalisasi di Januari 2019. 


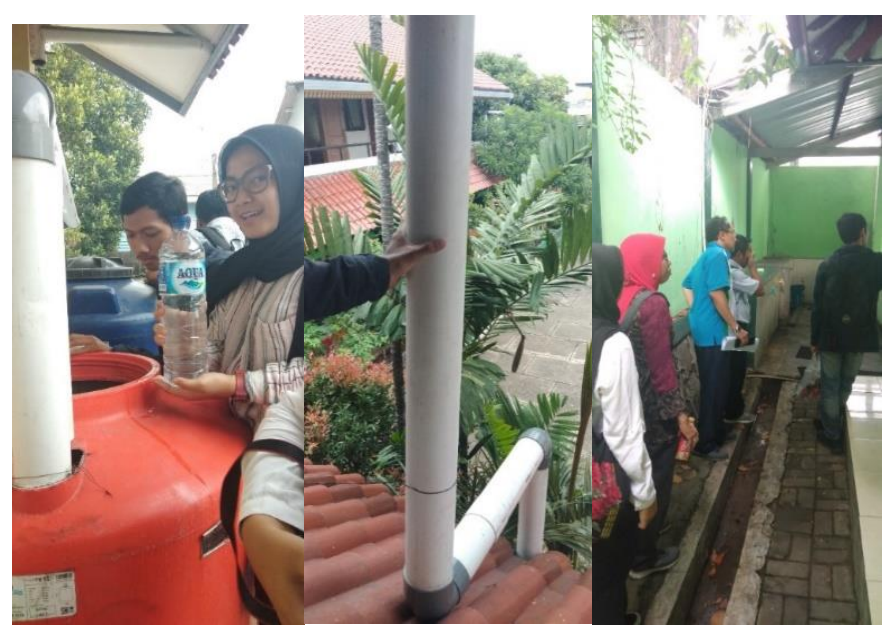

Gambar 1. Observasi awal di SDN Meruya Utara 12 pagi, SDN Meruya Utara 13 Pagi dan SDN Meruya Utara 15 Petang (Sumber: dokumentasi penulis)

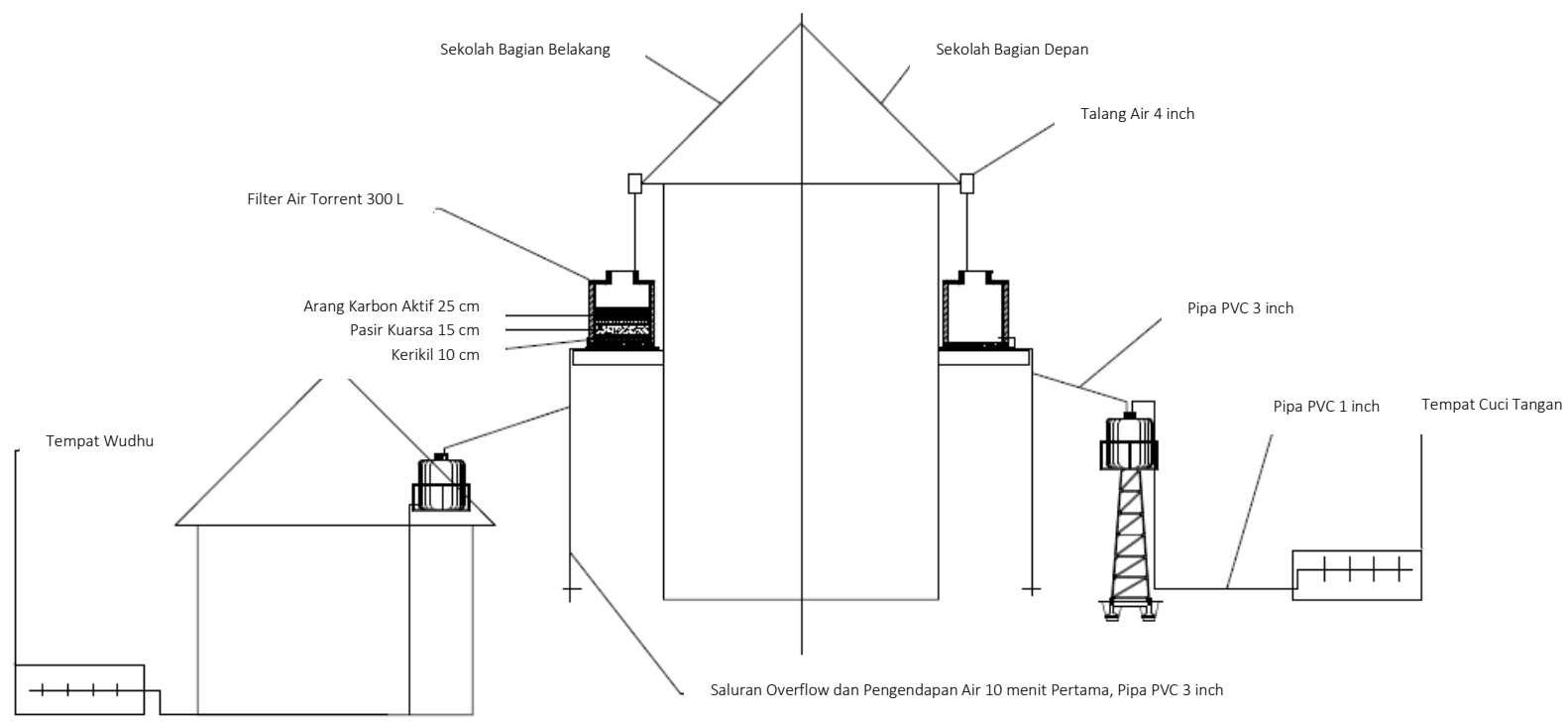

Gambar 2. Desain RWH

\section{HASIL DAN PEMBAHASAN}

Pada tahap pra desain, dari hasil observasi (Gambar 1), didapatkan hasil bahwa pihak sekolah tersebut telah memiliki Instalasi RWH, namun saat ini sudah tidak aktif dan masih membutuhkan perbaikan dalam instalasi tersebut agar bisa dimanfaat secara maksimal. Sekolah tersebut juga kurang mendapatkan pasokan air bersih dari perusahaan pengelola air setempat sehingga pihak sekolah masih menggunakan sumber daya air tanah dengan beberapa titik sumur bor. Setelah didapatkan informasi dari hasil observasi di lapangan, mulai dilakukan pembuatan desain Instalasi RWH serta penyusunan RAB. Desain RWH untuk SDN Meruya Utara 12 pagi, SDN Meruya Utara 13 Pagi dan SDN Meruya Utara 15 Petang tersaji pada Gambar 2.

Tahap kedua adalah pembuatan alat filtrasi sederhana. Rangkaian alat filtrasi ini 
dibuat dengan menggunakan torrent air ukuran 300 L yang di dalamnya berisi material-material yang dipakai untuk proses penyaringan. Setiap material-material (arang, pasir dan kerikil) tersebut kemudian akan dimasukan ke dalam tempat tersebut dengan urutan yang teratas adalah arang, kemudian diikuti oleh pasir dan arang. Ukuran tebal dari masing-masing bahan tersebut adalah $20 \mathrm{~cm}$ untuk arang, $15 \mathrm{~cm}$ untuk pasir dan $10 \mathrm{~cm}$ untuk kerikil.

Setelah susunan bahan-bahan sudah sesuai, pada bagian bawah dari torrent tersebut akan dipasang kran kecil untuk dapat mengalirkan air ke dalam torrent penampungan. Dalam pemasangannya kran dipastikan terpasang dengan kuat dan rapat sehingga nantinya tidak terjadi kebocoran atau kran terlepas.
Pengecekan dilakukan sebagai bentuk pengambilan data untuk mengetahui standar dan instalasi yang telah dibangun. Apabila kualitas air dianggap belum sesuai dengan harapan, maka perlu dievaluasi kembali susunan bahan-bahan dan komposisinya dan jika diperlukan dapat segera dilakukan penyusunan ulang.

Setelah instalasi dinilai sudah dapat digunakan, maka air hujan dapat ditampung di lokasi yang telah ditentukan. Air hasil dari penampungan diharapkan memiliki kualitas yang cukup baik dengan memiliki nilai pH yang mendekati standar dan tingkat kejernihan yang lebih baik dari sebelumnya. Hasil akhir penyaringan ini kemudian dilakukan uji laboratorium kualitas air.
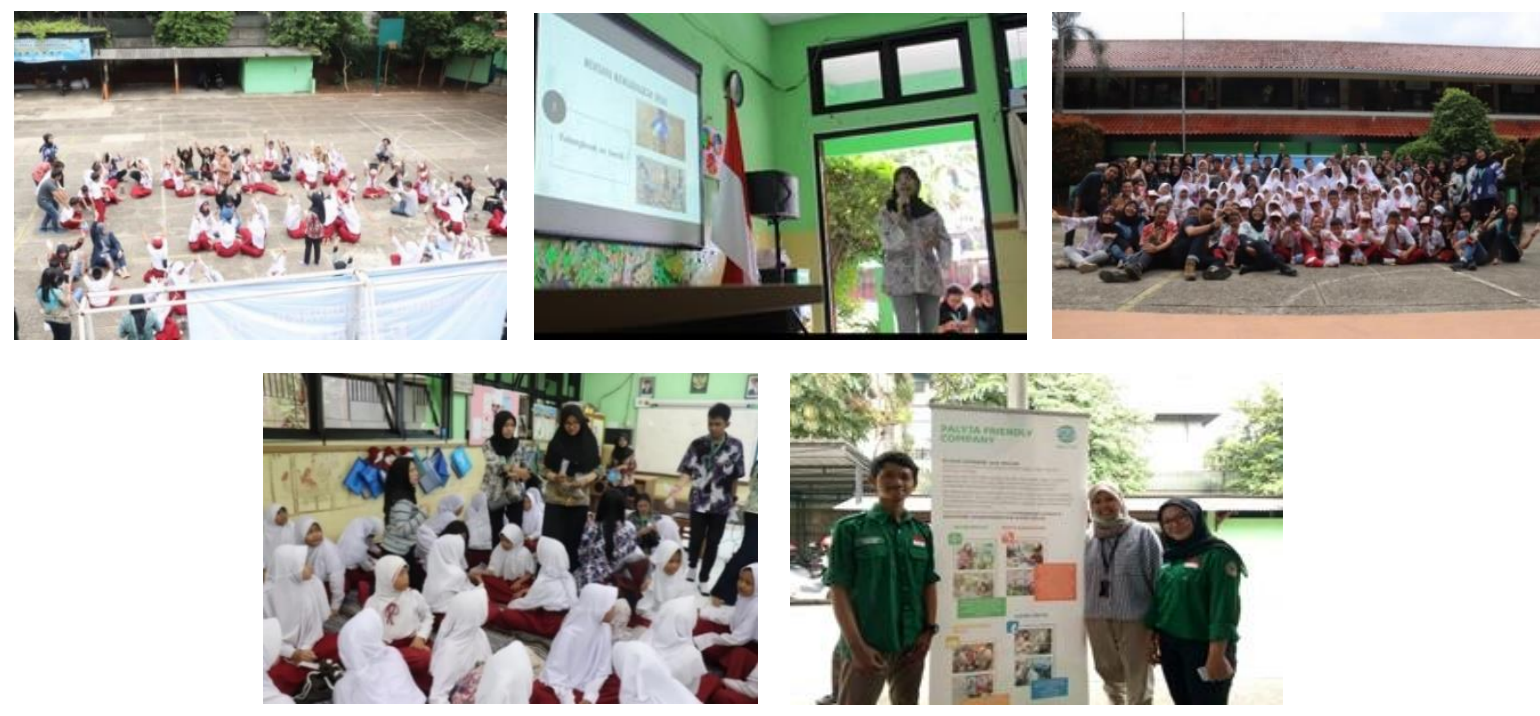

Gambar 3. Sosialisasi RWH

(Sumber: dokumentasi penulis) 
Apabila hasil uji setiap parameternya memenuhi syarat standar baku mutu air minum sesuai Peraturan Menteri Kesehatan No. 492 Tahun 2010, maka air hasil penyaringan tersebut layak digunakan untuk kebutuhan sehari-hari. Instalasi filtrasi sederhana ini merupakan alat yang direncanakan dapat mengatasi permasalahan kekurangan air di daerah yang sulit mendapat air bersih dan memiliki kondisi yang kering.

Tahap ketiga dari pelaksanaan program ini adalah sosialisasi kepada warga sekolah (Gambar 3). Proses sosialisasi terkait instalasi ini akan dilakukan di tiga sekolah, yaitu di SDN Meruya Utara 12 Pagi, SDN Meruya Utara 13 Pagi, dan SDN Meruya Utara 15 Petang. Proses sosialisasi ini meliputi:

1. Sosialisasi tentang konservasi air bersih

Pada sosialisasi ini, masyarakat khususnya warga sekolah disampaikan terkait dengan apa itu konservasi dan mengapa air bersih sangat penting serta cara yang mudah untuk menerapkan konservasi air. Materi berikutnya adalah bagaimana siklus hidrologis yang dibuat sesederhana mungkin dan menarik untuk dapat dipahami oleh para warga sekolah termasuk siswa-siswi di SD tersebut.

Sesi dilanjutkan dengan sesi tanya jawab secara interaktif dan santai. Sosialisasi ini dilakukan sebelum pembangunan instalasi RWH yang telah direvitalisasi.

2. Sosialisasi dan workshop Instalasi filtrasi sederhana

Sosialisasi ini dilakukan untuk memberikan pemahaman terkait dengan teknologi sederhana yang tepat guna untuk mengolah air hujan serta dijelaskan komponen, komposisi, cara kerja serta pemeliharaan instalasi filtrasi sederhana. Pada workshop juga dilakukan praktik langsung pembuatan filter sederhana.

\section{Pengontrolan program}

Pengontrolan ini dilakukan dengan cara pengecekan rutin dan evaluasi warga sekolah dalam menggunakan instalasi ini, yang diharapkan memperoleh hasil yang cukup optimal. Koordinasi antara kampus UB dan pihak sekolah terus terjaga dengan bantuan komunikasi whatsapp apabila mereka memerlukan konsultasi dan informasi apabila terjadi masalah operasional RWH.

Setelah instalasi terbangun dan sudah berjalan, dapat disimpulkan bahwa alat pemanenan air hujan berikut instalasi fiterasi sederhana yang dibuat sudah berfungsi dengan cukup optimal dan hasil olahan dari instalasi tersebut memiliki kualitas air yang relatif cukup jernih, sehingga warga sekolah dapat memanfaatkannya untuk kegiatan sehari-hari. 
Tanggapan warga sekolah terhadap hasil dari kegiatan ini cukup senang. Hal itu terlihat dari kesediaan Kepala sekolah, guru dan murid yang begitu antusias untuk membantu terlaksananya program ini serta penyediaan tempat. Sebanyak 2 tangki RWH digunakan sekolah untuk keperluan air berwudhu di mushola sekolah dan cuci tangan murid setiap harinya.

Aplikasi dari kegiatan ini bisa mengurangi terjadinya limpasan air yang berlebih, hal ini bisa nampak dari tempat yang sebelumnya sering kali mengalami kebanjiran, berdasarkan informasi warga sekolah, cukup seringnya sekolah mengalami genangan banjir di lapangan dan depan kelas yang diakibatkan oleh limpasan air yang berlebih yang berasal dari gedung sekolah. Hal tersebut dapat terlihat dari, didominasi nya area sekitar oleh bangunan yang padat. Sebagai gambaran jika estimasi curahan hujan sebesar $50 \mathrm{~mm}$ atau 0,05 $\mathrm{m}$ dari atap seluas $1 \mathrm{~m} \times 1 \mathrm{~m}$, maka akan mampu melimpaskan air sebanyak 0,05 $\mathrm{m}^{3}$. Massa air sebesar itu jika tidak mampu dialirkan oleh drainase karena kondisi area yang padat oleh bangunan maka dapat memicu terjadinya genangan atau banjir. Hal tersebut tentunya dapat dikurangi dengan menampung limpasan air yang berlebih itu, air yang tertampung bisa dimanfaatkan untuk kebutuhan di masa yang akan datang atau pada musim kemarau. Polutan yang terbawa oleh hujan dapat ditanggulangi dengan pembuatan filter, sehingga didapatkan air dengan hasil yang baik.

\section{KESIMPULAN}

Dari kegiatan ini dapat disimpulkan bahwa alat pemanenan air hujan (RWH) dengan kapasitas 2000 L dapat dioptimalkan dan mampu menyediakan air yang aman dan relatif lebih jernih dan mencukupi serta berfungsi dengan baik. Penggunaan air RWH ditempatkan pada dua titik yaitu di bagian depan sekolah untuk keperluan cuci tangan dan di mushola untuk keperluan berwudhu sehingga bisa mengurangi penggunaan air tanah untuk keperluan sehari-hari. Alat pemanenan air hujan (RWH) dapat meminimalisir limpasan air yang berlebih. Dahulu, sekolah sering mengalami genangan banjir yang berasal dari limpasan air yang berlebih dari atap gedung sekolah. Namun sekarang, air hujan telah ditampung tidak melimpas menjadi genangan dan dapat digunakan untuk keperluan di masa yang akan datang khususnya pada musim kemarau. Polutan yang terbawa langsung dari hujan dan instalasi penampungan mampu diatasi dengan adanya instalasi filtrasi sederhana. Melalui program ini warga sekolah menjadi paham mengenai prinsip kerja dan menerapkani RWH, cara pengoperasian alat RWH serta pemeliharaannya dengan pemberian materi serta workshop mengenai RWH. 


\section{UCAPAN TERIMA KASIH}

Terima kasih kepada Lembaga Pengabdian Masyarakat Universitas Bakrie, yang telah mendanai dan memfasilitasi untuk kegiatan PkM ini.

\section{DAFTAR PUSTAKA}

Abdulla, F. A., \& Al-Shareef, A. W. (2009). Roof Rainwater Harvesting Systems for Household Water Supply in Jordan. Desalination, 243(1-3), 195-207.

Achmad, M. (2011). Buku Ajar Hidrologi Teknik. Makassar: Universitas Hasanuddin Makassar.

Chiras, D. D. (2009). Environmental Science 8th Edition. Jones and Bartlett Publisher.

Latif, A. (2012). Pemanfaatan Air Hujan Melalui Teknologi Water Bank Untuk Memenuhi Ketersediaan Air Bersih Disalah Satu Desa Kabupaten Bandung Barat. Bandung.

Liaw, C. H., \& Tsai, Y. L. (2004). Optimum Storage Volume of Rooftop Rainwater Harvesting System for Domestic Use. Journal of the American Water Resources Association, 40(4), 901-912.
Helmreich, B., \& Horn, H. (2009). Opportunities in Rainwater Harvesting. Desalination, 248 (1-3), 118-124.

Kahinda, J. M., Taigbenu, A. E., \& Boroto, J. R. (2007). Domestic Rainwater Harvesting to Improve Water Supply in Rural South Africa. Physics and Chemistry of the Earth, 32, 1050-1057.

Sazaki, E., Alexopoulos, A., \& Leotsinidis, M. (2007). Rainwater Harvesting, Quality Assessment and Utilization in Kefalonia Island, Greece. Water Research, 41(9), 2039-2047.

Sharpe, W. E., \& Swistock, B. (2008). Household Water Conservation. The Pensylvania State University.

UNEP International Technology Centre. (2001). Rainwater Harvesting. Murdoch University of Western Australia. 
Indonesian Journal for Social Responsibility (IJSR) Vol. 2, No. 01, (2020), hal. 11-19 